\title{
Power relations: a catalyst in the building of flood disaster resilience capacities in the Orashi Region of Rivers State
}

\begin{abstract}
Climate change-related disasters have in recent years become a global phenomenon with catastrophic consequences. Africa has had most of the consequences of climate change related disasters, resulting in monumental urban and rural flooding, widespread casualties, displacements, loss of property and sources of livelihood. Given the long-term implications of climate change, it is critically important to understand how vulnerable communities respond to the menace occasioned by flooding. The impact of the flooding is felt more in low-lying communities situated along the coastal fringes leaving inherently vulnerable communities to the vagaries of flooding. However, despite of their vulnerability to flooding disasters, some people displayed resilience capacities more than others because of their apparent access to resources and power within and outside their localities. The study investigated the issue, through the application of the qualitative approach that drew the Bourdieusian theory of practice, deploying the analytical concepts of fields, habitus and species of capital to gather useful information from relevant focus groups to understand how various forms of power was employed to capture resources that enhanced resilience capacities in the seasonal flood prone Orashi region of Rivers State of Nigeria. Following the outcome of the analysis of the information gathered from the focus group and a review of relevant literature, it was revealed that most of the vulnerable population displayed some ingrained disposition and the deployment of indigenous knowledge and social capital for adaptation to survive flood disasters. It is therefore concluded that dynamics of power is a key factor in the resilience capacities of the population of the study.
\end{abstract}

Keywords: catalysts, flood disaster, orashi region, power relations, resilience
Volume 5 Issue 6 - 2021

\author{
Ibama Brown,' Tari Eyenghe, ${ }^{2}$ Sodieari \\ Henderson Boyle ${ }^{3}$ \\ 1,2Department of Urban and Regional Planning, Rivers State \\ University, Port Harcourt \\ ${ }^{3}$ Institute of Geosciences and Environmental Management, \\ Rivers State University, Port Harcourt
}

\begin{abstract}
Correspondence: Ibama Brown, Department of Urban and Regional Planning, Rivers State University, Port Harcourt,
\end{abstract} Nigeria,Email ibabrown@yahoo.com

Received: October 14, 2021 | Published: December 20, 2021

\section{Introduction}

In recent times there has been a phenomenal increase in the frequency of flooding especially in areas with lower latitudes in Africa and Asia. ${ }^{1,2}$ Contemporary flood disaster researchers have maintained that flooding is one of the most hazardous and frequently occurring natural disasters, attributed to distortions in natural environmental characteristics, like the vegetation, hydrology, and anthropogenic actions. These anthropogenic actions include land reclamation, river and flood path diversion in vulnerable localities, changes in the landform, and distortion of the natural environment, which over the years, induces changes in the intensity and frequency of flood. 3,4

Also, seasonal variations in the river flow pattern and precipitation contribute to inter-annual changes because when there is an increase in precipitation, there is a commensurate rise in the river water levels, resulting in flooding in vulnerable communities. ${ }^{5}$ The El Nino and El Nina effects are contributory factors to the asymmetrical inter-annual inconsistency of African flood disaster trend, and climate change, land cover, economy, population affects regional disparities in flood disaster over time. ${ }^{6}$ Flooding symbolises a physical challenge in most rural and urban settings; it occurs as a result of persistent rainfalls in some places, causing a disparate flow between the accumulation and percolation rates of runoffs due to increased pressure and volume of water during and after rainfall. ${ }^{7}$ Besides, developing the built environment in the form of city development or improvement with impervious surfaces often leads to flooding. ${ }^{8,9}$
Anthropogenic actions are responsible for the dominant changes in the landscape that engender flood disasters in vulnerable locations. ${ }^{10}$ These human-induced activities involve building on floodplains that distort the flow dynamics of runoffs. ${ }^{11}$ Changes in human behaviour and evolving natural circumstances also cause increased flood vulnerability in most environments. ${ }^{1}$ Agriculture-related activities of local farmers and communities also increase the chances of flooding in most rural enclaves because they do not apply best practices in rural land-use and become prone to flood associated disasters. ${ }^{12}$ Power in the context of this research indicates those who had access to symbolic power within the local government and how they used it to influence decisions and controlled the flow of resources during the flood. They include the local government chairman, the councillors, some past and present political office holders, and the king of the clan.

\section{Literature review}

\section{Overview of flood disaster in the orashi region}

Nigeria has increasingly become susceptible to flood-related disasters in recent years and has exposed many Nigerians to the vagaries of flooding and its attendant challenges..$^{13}$ The frequency and type of flooding in Nigeria have also increased throughout the last four decades and occur as urban flash floods, channel, and coastal floods. ${ }^{14}$ Experiences of flooding have been a challenge, and the National Emergency Management Agency (NEMA) adjudged the 2012 flood episode as one of the worst in the recorded history of flooding in 
Nigeria before 2012. The flood affected 30 out of the 36 states of the country, leaving behind its trail about 2.3 million displaced persons with about 7 million persons indirectly affected, 597, 476 housing units destroyed and 363 recorded deaths. Other noticeable losses during that flood episode were the submergence of several hectares of arable land leading to the distortion of ecosystems, livelihood chains, displacement of wildlife and the destruction of other critical infrastructure. ${ }^{14}$

The Niger Delta region of Nigeria has over the years been inundated with a myriad of challenges occasioned by the variations in the climate which had left the region susceptible to extreme environmental and ecological threats like flooding. ${ }^{15-19}$ Besides climate change related vulnerabilities plaguing the Niger Delta region, continuous exploration of petroleum resources has further rendered the fragile ecosystem of the Niger Delta region susceptible to the vagaries of climate variations. These variations exist in the form of a microclimate which has left the region with a different climatic condition that enables flood disaster to become a common occurrence with no sustainable solution in sight. ${ }^{20}$

The Orashi region of Rivers State is the study area. It is in the Niger Delta region of Nigeria, and conservatively covers an approximate landmass of $70,000 \mathrm{~km} 2$ which represents one of the most extensive wetlands globally. It is an ecological zone located between latitude $4^{\circ}$ and $6^{\circ}$ North of the equator and longitude $5^{\circ}$ and $7^{\circ}$ East of Greenwich. It is also located on a coastal plain with fluvial deposits traversed by several rivers and tributaries which makes the area vulnerable to flooding. ${ }^{11}$ The delta consists of four ecological zones lowland rainforest, freshwater swamp forests, mangroves, and coastal barrier islands. It has dry and wet seasons, with poorly drained low-lying terrain and soil that encourages erosion and flooding occasioned by intense precipitation and river discharge in the wet season. ${ }^{21}$

As a region, it comprises four local government areas; Abua/ Odual, Ahoada East, Ahoada West and Ogba/Egbema/Ndoni with six distinct ethnic nationalities; Abua, Egi, Ekpeye, Engenni, Kugbo, and Odual $^{22}$ with diverse social, cultural, economic, and political orientations. According to the 2006 national census records, the region has a combined population of 983,170 persons (NPC 2006) who are predominantly agrarian and subsistence fisher folks.

Over the years the region has been continuously inundated with floodwaters as a result of anthropogenic activities in the form of agricultural activities, oil and gas exploration and exploitation leading to a loss in the vegetation. ${ }^{18}$ With the numerous anthropogenic activities, the flood susceptibility level in the region is very high because its coastal elevation lies between $4 \mathrm{~m}$ and $7 \mathrm{~m}$ which is significantly impacted by continual eustacy. ${ }^{23}$ The nature of the terrain engenders tidal surges because of rising sea levels and sometimes after intense precipitation, the low-lying coastal fringes submerge leading to flooding that could be as high as $3.2 \mathrm{~m}$ in some locations depending on the height. ${ }^{17}$

Most of the vulnerable populations in the region are faced with challenges arising from the flooding which has become a constant phenomenon in their environment, with no help from any source to build their resilience capacities or to put in place mitigation approaches. ${ }^{16}$ This scenario has caused the vulnerable communities to develop their resilience capacities to prevent the loss of livelihood sources as a community. ${ }^{24}$

Vulnerability and resilience are two different yet related concepts that represent the response of actors and social systems regarding change occasioned by surprises and shocks in the environment. ${ }^{24}$
Vulnerability expresses the state of individual and group susceptibility to danger, powerlessness and peculiarity to social and environmental changes occasioned by exposure to disturbances and the ability to adapt and build resilience capacities. ${ }^{25}$ In this context, vulnerable communities have incrementally continued to build their resilience capacities by adopting indigenous knowledge to combat the risk associated with the flood. ${ }^{26}$ Resilience as a notion stems from resistance, coping, adaptation, and recovery ${ }^{27}$ which has over time gained several connotations based on the contextual application of the notion. ${ }^{28,29}$

Resilience as an idea has had several meanings depending on the context and intent of the researcher. For Matyas ${ }^{30}$ the application of resilience to natural hazards entails the ability of vulnerable communities to design how to cope, adapt, accommodate, and recover from the consequences of natural disasters. Timmerman ${ }^{31}$ was first to identify the need for designing a framework on how to cope, adapt, accommodate, and recover from flood-related disasters. Such a framework witnessed incremental evolution over the years primarily in the global north with recorded achievements in science and technology. However, in the global south, there have been little improvements regarding the building of disaster resilience capacities due to the prevalence of the application of indigenous knowledge to build resilience capacities during and after any natural disaster which indicates the need for some form of external assistance Figure $1 .{ }^{24}$

\section{Impact of flooding}

Flooding is a multifaceted phenomenon, and its impact encompasses the connection between people, social systems, and the natural environment because of the underlying destructions as the aftermath of every episode. The impacts are more devastating within the immediate vicinity of the flood because of the lives and properties lost in most circumstances, and when there is no prior information regarding the flood. Distortion of the livelihood chain in vulnerable communities is one of the significant impacts of flood disaster because most people are displaced leaving a dysfunctional society behind, with the loss of livelihood sources. Production and purchasing powers also decline as a result of flood disasters because of damages to the infrastructure which causes disruptions to sources of potable water supply, communication routes, transport and healthcare facilities. These challenges increase the vulnerability of the affected communities which often lead to an additional cost of getting these services provided, such as relocation of the affected population.

Getting these services restored often requires substantial financial resources which impact the level of production and purchasing power because most times capital is diverted from other sectors to get the system back up and running. Other impacts include mass migration from the affected areas in search of better sources of livelihood because, with frequent incidents of flooding, the active vulnerable population often move to other places with prospects of economic prosperity. Such a migratory trend often leaves the vulnerable communities depopulated, while the receiving locations sometimes get overpopulated, and facilities overstretched. There are also negative health impacts of flooding as most of the vulnerable people suffer psychosocial effects due to the trauma of displacement, bereavement, and loss of properties occasioned by the flood. ${ }^{32}$ The impact of flooding could be so severe that in some extreme situations there is a clog in economic development as investors move away from such areas to relatively safer locations; at the same time, political actors use it as an avenue to deprive the vulnerable populations of the needed resources. 


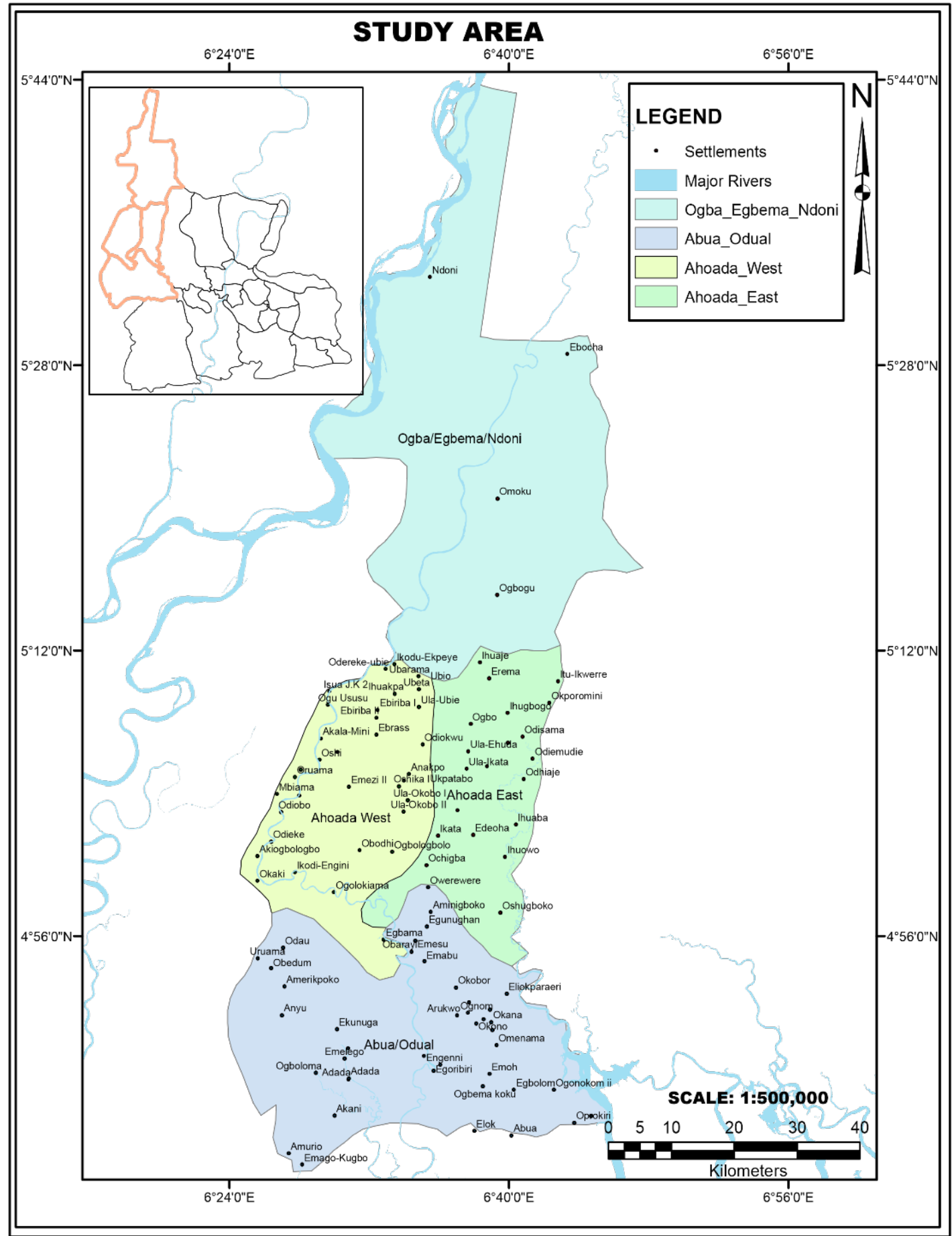

Figure I Map of Orashi Region Showing The Study Area.

Source: Rivers State Ministry of Lands and Survey, 2018.

Flooding has over the years been identified as a causal factor responsible for the stunted economic development of most African urban and rural communities. ${ }^{33}$ In the property sector, for instance, flooding often leads to the reduction in the value of properties in flood-prone and devastated areas which affect returns on investments in that sector leading to reduced economic power. ${ }^{34}$ There are visible impacts of flood disaster on the tourism sector as most tourist destinations situated in coastal cities in the global south have been continually inundated by episodes of flooding which has elicited calls for concern. These calls have not received the required attention, and these vulnerable destinations are increasingly becoming unpopular destinations leading to incremental loss of revenue and other associated benefits. ${ }^{35}$

This study aims to investigate how power relations and access to political power produce differentials in flood disaster resilience in Rivers State, Nigeria. 


\section{Flooding in the context of the global south}

Flooding has very devastating consequences such as poverty, lack of infrastructure and weak governance in most African communities because most of the vulnerable population cannot withstand the challenges occasioned by extreme weather conditions. These inadequacies make communities in the global south vulnerable to the vagaries of increased flooding because, they are the manifestations of deliberate human free choice which has incapacitated cities leading to a complete makeover of the ecological and environmental processes. ${ }^{33}$

In most circumstances, the vulnerability of communities in the global south results from limited opportunities and an apparent lack of access to power structures. Also, the inability to access these power structures affects every aspect of society regarding the building of flood disaster resilience which often engenders limited responses at such times by the state and vulnerable communities. These limited responses by the state and vulnerable communities are a direct consequence of limited availability and accessibility to resources. ${ }^{36}$ Power structures further determine the types of flood defences, policies controlling land use changes such as the development of floodplains and deforestation in most vulnerable communities. Furthermore, power structures in the global south sometimes promote or inhibit the ability of actors to undertake actions that would build the resilience capacities of the vulnerable population such as accessing and controlling the flow of resources during and after any flood disaster episode. ${ }^{36}$ The outcome of the ability to access power structures in the global south determines the level of risk, exposure, and vulnerability of communities because adequate access reduces the chances of colossal damages and builds disaster resilience. ${ }^{37}$

Building resilience capacities to survive flood disasters in vulnerable communities in the global south encompasses techniques that are unique to such communities. These strands of unique techniques are embedded in their indigenous knowledge as a people with different connotations such as traditional knowledge, local knowledge and inter-generational knowledge which has been acquired and passed on from one generation to another. ${ }^{38,39}$ The United Nations Educational Scientific and Cultural Organisation (UNESCO) in 2016 further identified the role of indigenous knowledge in climate change adaptation discourse in the global south.

There is a growing body of knowledge that has identified the actions taken by communities susceptible to flooding in the global south as indigenous to them, aimed at building their resilience capacities to flooding and other disasters. These include lay knowledge, traditional knowledge, inter-generational knowledge which has also proven to be a source of survival in a disaster ${ }^{38-41}$ Most of the vulnerable communities have over the years continued to deploy indigenous knowledge which has become their inclination to build flood disaster resilience. However, most communities in the Orashi region are precariously vulnerable whenever it floods which might be related to the lack of requisite resources to build their resilience capacities, either as individuals or as a community. Hence, they resort to reacting in ways that do not build their resilience, and minimal attention has been given to ascertain the causal factor regarding their reactions. Furthermore, while most of the people are vulnerable to the threats occasioned by the flood, some seem more resilient than others engendering differentials in their resilience capacities.

Drawing on the Bourdieusian lens of field, habitus, capital, and power, these represent contemporary tools that support empirical research because, they contrast with grand theory and speculative philosophy in contemporary research ${ }^{42}$ making them appropriate to fill in the research gap. The Bourdieusian concepts mirror power relations and power structures in the form of symbolic power, class domination and the reproduction of social hierarchies ${ }^{43}$ and identifies embedded dispositions displayed by individuals and communities when faced with life threatening situations. ${ }^{44}$ These concepts also elucidate the description of how actors deploy social positions to access resources in the society that engender differentials in flood disaster resilience and are useful regarding the study of differentials in flood disaster resilience in the global southern context which this research aims to highlight.

\section{Theoretical underpinning}

Pierre Bourdieu is a notable sociologist whose works reflect an allinclusive ethnographic perception of the French culture regarding the formation and reproduction of class structure in society. Fundamental to Bourdieu's treatise is an integrated procedural and theoretical process that tends to overcome some of the existing sociological dichotomies in society regarding agency-structure, objectivesubjective, theoretical-empirical, and symbolic-material. Other sociological interests of Bourdieu revolve around understanding the true rationality behind social action and daily interactions, besides, understanding domination and relations of power within society. Bourdieu deployed several concepts like field, habitus and forms of capital which include social, economic, symbolic, and cultural in order to develop reflexive sociology. Bourdieu's work was used to mirror the behavioural consistencies connected with social structures in society such as ethnicity, gender, and class without portraying the social structures as deterministic of the behaviour or the agency of the individual.

Using the Bourdieusian lens as a theoretical framework in this study, this is an attempt to explore the workings of the social system on the premise that it would present an in-depth and nuanced understanding of the complexities and dynamics in the experiences of those affected by the flood in the study area. It aims to understand how power is reflected in the actions of the various actors across the study area.

\section{Concept of field}

Fields from Bourdieu's perception represent organised arenas where actors with dominant and subordinate positions interact and engage each other in accessing the specific forms of capital found within that field. These structured spaces are evident in several organisations in a society which in most cases engenders cooperation among the actors in the various fields to foster long-lasting relationships. Instances where Bourdieu extensively applied the concept of field include education, science, religion, arts, taste, and law. ${ }^{45}$ Bourdieu deployed the spatial metaphor in the concept of a field to elucidate real-life scenarios of how actors in the field play a social game leading to subjective incorporation of objective possibilities in the course of competing for capitals. These fields cannot exist and thrive without the presence of capital. Bourdieu identified four capitals: economic, social, cultural, and symbolic. Access to these capitals in the field is relatively dependent on the possession of social position by the actors. Bourdieu described the field as a:

network, or configuration, of objective relations between positions,' where the 'positions' are defined 'objectively' in their existence and the determinations, they impose upon their occupants, agents or institutions, by their present and the potential situation in the structure of distribution of species of power (or capital) whose possession commands access to the specific profits that are at stake in the field. ${ }^{46}$ 
Bourdieu's description of the field indicates that the subordinate and dominant actors often characterise each of the structured social spaces that represent a field. Both sets of actors often express the intent of getting access and exerting a monopoly of control over the reproduction mechanisms, including the prevailing power relations inherent in the field. Interactions of the actors often characterise the field as an evolving relational social space that engenders the actors to think or act dialectically and relationally. ${ }^{44}$ To elucidate these dialectic and relational characteristics of the actors in each field, Bourdieu ${ }^{47}$ further describes the field as a "separate social universe having its laws and functioning independently of those of politics and the economy," and they are "autonomous universe endowed with specific principles of evaluation of practices and works".

Autonomy of the field in Bourdieu ${ }^{47}$ identifies each field as unique because each field relatively decides the class of actors that would participate in the struggle for the limited resources in that field. However, the field as a concept has been adopted by researchers differently from Bourdieu ${ }^{46,47}$ description of the field such as an avenue to reproduce social class and taste. ${ }^{48,49}$ The field across the different spheres of human engagement exhibit objective and subjective relations of power in addition to specific principles guiding the interactions. These specific principles reflect the autonomy of each field as a social space and further engender dynamism among the actors to allow different interpretations of what the field portends for each class of actors.

Bourdieu contends that the core structure of any field is determined by objective power relations which makes the whole system of fields in every sphere of society revolve around the existent dynamics of power. The field provides the platform for actors with similar higher cultural capital to access and control other capitals by dominating other actors in the field. Actors with higher cultural capital characterise the activities in the field such that they become the dominant class with influential positions based on the volume of capital they can access and control, thereby making the field accessible to only those within that class. ${ }^{50}$ Bourdieu describes this class-centrism as:

considering as the 'natural' (in other words, both as a matter of course and based on nature) way of perceiving which is but one among other possible ways and which is acquired through education that may be diffuse or specific, conscious, or unconscious, institutionalised, or non-institutionalised. ${ }^{47}$

\section{Concept of habitus}

Habitus as a concept is very important to Bourdieu's distinctive sociological ideology and has been the core of his interaction in the social sciences. Habitus has also been one of the most widely misunderstood, yet keenly contested and most misused concepts of Bourdieu; it is easy to document, yet very challenging to explain due to its unpredictable and fluid nature. Succinctly put, habitus encompasses individual and group exhibiting dispositions and perception patterns in order to overcome subject-object polarity. It is achievable by engraving some independent, physical actions with an objective social force that allows the most seemingly subjective actions of individuals to get social interpretations in society.

Bourdieu used habitus to explain the consistencies of dispositions associated with social structures among actors in society, like gender, taste, ethnicity, and class such that the social structures are not seen to be deterministic of perception regarding the agency of the individual. Habitus describes the embodiment of social structures and reminiscences in the agents because it serves as a set of internal dispositions that shape the perception and also reflects the external structures of the individual regarding the social world. In any society, different classes and groups have different legacies derived from the amount of capital they can access which structures them along with social spaces that serve their purposes. The implication of such structural differences has engendered these actors to develop different perceptions and attitudes in the social world evident in their taste and cultural preferences. The fallout of these structures on the dispositions of the individual signifies habitus is embedded in social structures but does not regulate nor shape the disposition and behaviour of the individual. Instead, the individual is inclined to act in the context of the social structures that have shaped the individual, because these social structures are embodied..$^{43}$ Bourdieu describes habitus as follows:

The dispositions associated with an existing class of specific conditions of existence produce habitus, systems of durable, transposable dispositions, structured structures predisposed to function as structuring structures, that is as principles that generate and organise practices and representations that can be objectively adapted to their outcomes without presupposing a conscious aiming at ends or an express mastery of the operations necessary in order to attain them. ${ }^{43}$

From the perception of Bourdieu, the individual serves as a sieve that engages and adopts the external influences from the social world in the form of objective practices that replicates individual dispositions to behave and act in a specific way. Habitus is learned through structural conditions that are enabled by social interactions to form distinct practices that shape the fundamentals of the objective structure. These dispositions, in turn, inform and reproduce objective practices that influence the objective structure; with time, it makes the relationship between the objective and subjective dimensions symbolise the nature of habitus. It is such that the main habitus of the individual developed from childhood becomes an enduring disposition compared to later developed habitus occasioned by association within the social world..$^{50}$

\section{Concept of capital}

Capital as a concept is one of the more accessible theories in which Bourdieu deployed economic metaphors to elucidate abstract collective issues, like ideas, habits, and beliefs with the assignment of quasi-monetary value to them. ${ }^{51-54}$ Capital, in the context of Bourdieu, represents, the enabling force to exert control over others regarding available resources in the field such that once a privileged few acquire the resources, they have the power to control the activities within that field. Having access to capital in the field changes the social position of the individual from what it was to a new status associated with the control of the distribution of resources in the field. Bourdieu describes capital as "accumulated labour, which when appropriated on a private basis by agents or groups of agents, enables them to appropriate social energy in the form of reified or living labour". ${ }^{52}$ Bourdieu's description of capital represents the struggle for the acquisition of power by groups and individuals in order to control others who do not have access to the resources. Capital becomes a highly sought-after commodity which gives a distinct advantage to those who have access to it and disadvantages those who do not have access to it.

An exhaustive view of the Bourdieusian concept of capital evokes the platform to examine the social inequalities that exist in the social world relative to accessing capital. Capital depicts anything that could be used to influence the actions of an individual or group to accomplish an anticipated objective. Thus, the theorisation of capital by Bourdieu is contextually sensitive because of the activities of the dominant class in accessing capital and using it as a tool for control of the subordinate class in the social world. 
Bourdieu highlighted three forms of capital economic, social, and cultural. ${ }^{53-55}$ Among these forms of capital, economic capital from Bourdieu's inclination takes precedence over other forms of capital premised on the capitalist society emphasising monetary resources. Access to economic capital grants individuals accesses to other forms of capital like cultural, social, and symbolic capitals because they have the potential of being converted to economic capital. Bourdieu's three forms of capital are convertible from one form to another, and the convertibility stands as the actual rationality behind the functioning of the capital. A challenge with convertibility of capital from one form to another is that the conversion process does not happen simultaneously. For instance, an enormous investment in social capital could yield very little economic capital which makes the conversion rate very difficult to establish in the social world..$^{54,55}$

\section{Economic capital}

Economic capital is one of Bourdieu's forms of capital which represents the product of other converted capitals translated to wealth comprising of tangible resources and merchandises, material and financial wealth. Characteristically, economic capital is material wealth that is sometimes evident or veiled in other types of capital but serves as currency or tangible assets that are convertible into monetary terms. Economic capital is relatively accessible to members of a specific group or household and represents the most important form of capital. It also forms the underlying reason for the conversion of other capitals, and its pursuit specifies the position of the agent in the field. ${ }^{54}$

The most tangible form of Bourdieu's capital is the economic capital because of its close alignment to the definition of capital by economists which refers to it as materials and financial resources that can be converted directly to other sought-after goods and services. In a disaster situation, vulnerable individuals who have access to more economic capital tend to build their reliance capacities in times of a disaster because of its positive effects. Economic capital is a function of social relations of inheritance, power and household features of production which characterises the household as a social and economic unit. It makes economic capital transferable through several generations which reflects the natural needs of the agents and the creation of social and economic status. ${ }^{56}$

\section{Cultural capital}

Cultural capital exists in three forms namely the embodied, objectified, and institutionalised. ${ }^{57-59}$ Embodied cultural capital depicts ingrained skills, language, behaviours and knowledge within a group or an individual in the social world. Acquisition of embodied cultural capital by the individual is a function of time and cannot be transferred from one person or one group to another neither can it be gifted as such. Embodied cultural capital translates to the ability and perception of an individual regarding what activities that interest the individual to partake in such as cultural objects like pristine paintings, or literary works. Embodied cultural capital is a function of the availability of appropriate fields and capital that engenders habitus because the perception of the individual regarding those items is the result of the ingrained dispositions over time. To achieve the status where embodied cultural appeals to the individual requires investment in time, resources, inculcation, and assimilation over time; this will reflect what cultural objects and tastes appeals to the individual. Bourdieu describes the scenario as the "dispositions of the mind and body". ${ }^{60}$ Dispositions associated with embodied cultural capital often represent the collective external and internal processes of an individual or a community assimilated and occasioned by constant interactions over the years. It becomes part of the community and individual because it resonates within them such that embodied cultural capital then reflects "the ensemble of cultivated dispositions that are internalised by the individual through socialisation and that constitute schemes of appreciation and understanding". ${ }^{49}$

Objectified cultural capital represents physical objects that have significance attached to them by the individual or the community based on the perception, class and sense of taste and the level of access to capital. They are mainly acquired physical objects enabled by the possession of economic capital by the individual or community, which has the potential of being transferred or gifted as such from one individual to another. Bourdieu indicated instances of objectified cultural capital to be cultural goods which include machines, books, pictures, dictionaries, instruments, and the likes. ${ }^{61}$ There is the argument that the omission of Bourdieu regarding the classification of physical objects acquired with economic capital as objectified cultural capital does not reflect its true representation. The reason is that the values attached to physical objects such as artefacts vary from location to location and depends on the values, beliefs system, norms and culture of the people. Also, possession of objectified cultural capital by an individual does not automatically imply that the value of such object is appreciated or understood rather, it is a function of the presence of significant traits of embodied cultural capital. ${ }^{62}$

Institutionalised cultural capital represents credentials that confer on the bearer a constant, conventional, legally assured value regarding culture, a public transformation that engenders independence between the type of cultural capital and the bearer. ${ }^{53}$ Implicitly, the conferment of institutionally recognised cultural capital enables the holder to compare qualifications. Comparison between the holders of institutionalised cultural capital enables the establishment of conversion rates between economic and cultural capitals which guarantees the financial value of the academic qualification and creates the possibility of exchanging it for another. The outcome of the conversion of economic capital to cultural capital establishes the value relative to cultural capital, and the possessor of the qualification relative to others with qualification, with a similar token, the economic value of its exchange in the labour market.

\section{Social capital}

Social capital ${ }^{54-56}$ entails the networks of relationships and the relationships possessed by an individual to highlight the relative strength inherent in families and communities. In context, having relationships and belonging to a network of relationships engender the individual to access resources and further confers a distinct benefit on the individual to accumulate more capital. These relationships and the network of relationships are evident practically fuelled by symbolic and material exchanges that bind the members within the network. These networks are accessed differently based on the status, orientation, disposition, and interest of the members at the point of belonging to the group. These networks of relationships are sometimes socially constructed and assured based on the application of a collective connotation in the form of family, club, school, social class, tribe, profession, and occupation. At the same time, they are also guided by a set of foundational actions which enables them to form a bond that underpins the relationship to establish objective relationships of proximity in the physical, social and economic space. ${ }^{57}$

\section{Bourdieu describes social capital as:}

the aggregate of the actual or potential resources which are linked to possession of a durable network of more or less institutionalized 
relationships of mutual acquaintance or recognition made up of social obligations ('connections'), which is convertible, in certain conditions, into economic capital and may be institutionalized in the form of a title of nobility. ${ }^{55}$

Bourdieu's description of social capital indicates that the volume of social capital an individual possesses is a function of the magnitude of the network of relationships and volume of other forms of capital (cultural, economic, or symbolic), at the same time as those possessed by each member of the network. Implicitly, social capital is not entirely independent, because the interchanges underpinning the relationship exercise multiplier effects on the capital because of minimum objective consistency among the members of the group regarding the capital. ${ }^{55}$

\section{The dark side of social capital}

The basic idea behind the existence of social capital among any social group is to achieve collective aims through shared norms and ideology for the improvement of the welfare of members when the need arises. In every sphere of human endeavour, social capital engenders unity of purpose, but when it becomes a source of deliberate deprivation, oppression, social exclusion, and social inequality, then it becomes a murky experience. The dark side of social capital is a situation where the communal ties, collective beliefs and norms that bind becomes the challenge of the social group. It reflects the efforts of individuals trying to exploit and influence trust to achieve the specific interest of a few within the social group which could sometimes lead to the unintentional and intentional social exclusion of some members. ${ }^{63}$ Besides, the exclusion of members engenders the formation of class within the social group that fosters prolonged deprivation and poverty of those outside of the class. Indications are rife that the formation of class within the social group leads to endemic social inequality as vulnerable people continue to struggle to access resources. ${ }^{64}$ Sometimes the dark side of social capital encourages the formation of gangs which concomitantly spike the criminality within and away from the network.

\section{Concept of resilience}

Resilience as a concept stems from the field of ecology and gained prominence in several fields like psychology and sociology. Resilience has been one of the main drivers in social sciences discourses such as environmental planning, economic geography, psychology, and disaster studies which have been using the concept prominently. ${ }^{65}$ The usage of the term resilience across various research fields has caused its definition to become indistinct. ${ }^{66,67}$ Resilience generally, but not exclusively attributes its focus on the need to reduce damage in the eventuality of unexpected natural or anthropogenic distortions in the physical environment. ${ }^{68,69}$

\section{However, Ungar $^{70}$ defined resilience as:}

the context of exposure to significant adversity, whether psychological, environmental, or both, resilience is both the capacity of individuals to navigate their way to health-sustaining resources, including opportunities to experience feelings of well-being, and a condition of the individual family, community and culture to provide these health resources and experiences in culturally meaningful ways.

Resilience underpins the ability of the affected population to recover to a near-normal state of being after any disturbances. The social environment which encompasses culture, personal characteristics and family contributes significantly to the building of resilience. ${ }^{70}$ Researchers have established a commonality in the building of resilience capacities in any disaster scenario which involves the mobilisation of resources, in addition to human adaptation structures that reflect the capacity to withstand and/or recover from any disaster or stress scenario..$^{71-74}$

Increasingly resilience as a concept has gained global significance in its application by researchers because it involves the assemblage of both human and material resources, and in some situations presents adaptive strategies to withstand external and internal stressors in the environment. These stressors often distort socio-ecological systems to test the capacity to absorb anticipated and recurring disturbances. ${ }^{75} \mathrm{~A}$ detailed view of the resilience literature evinced contrasting divides between researchers which indicates two polarities on the resilience spectrum. Such polarities stem from researchers who focus on adaptation enabled systems and researchers who focus on disaster recovery systems of resilience. These polarities are evident within the social non-equilibrium and social equilibrium concepts of resilience. The social non-equilibrium concept deals with a situation where resilience is established as the ability to adapt and change in a disaster scenario with no possibility of returning to the normal state, while the social equilibrium concept establishes resilience as the ability to return to the normal state after a disaster scenario. ${ }^{73}$

\section{Resilience in disaster management}

This research has been deliberately designed to explore resilience within the framework of communities vulnerable to flood disasters in the Orashi region of Rivers State, Nigeria, intending to identify the role of power in flood disaster resilience. In the field of disaster management, several researchers have looked at the notion of resilience as it affects the individual and the community collectively. ${ }^{77-80}$ Researchers are of the opinion that contemporary flood disaster management systems prevalent in most societies globally are tailored to be response-driven and excessively dedicated to actions regarding the outcome of any disaster. ${ }^{81,82}$ In recent times, a lot of vulnerability and risk reduction plans of actions have augmented the usual responsedriven approaches to encourage resilience building to advance predisaster planning processes by vulnerable societies. ${ }^{82}$ Evidence from several studies indicates that response-driven approaches in managing disaster do not encourage the building of resilience in most disaster prone vulnerable communities in the global south..$^{83-87}$

At the turn of the last century, several community-based vulnerability and risk reduction schemes away from the resiliencebased process emerged to augment the existing traditional disaster management structures. These community-based vulnerabilities and risk reduction programmes focused more on the external factors such as risk and vulnerability amplification schemes that were beyond the control of the communities. ${ }^{88-90}$ Such vulnerability and risk augmentation schemes were not enough to build the required resilience of the individual and community. As such, further augmentations were required to achieve strong community and individual resilience which required sound policies, firm institutional practices and internal community structures during and after any crisis to enhance their resilience capacities. ${ }^{81}$

\section{Individual resilience}

As the concept of resilience gains momentum globally, researchers are beginning to identify the importance of the connection between the individual, community, and the institutions in building resilience during and after a disaster. ${ }^{91,92}$ For instance, Doron ${ }^{92}$ established that the best treatment for acute stress and trauma is individual resilience, but for long-standing stress occasioned by a disaster, community resilience aids recovery faster. Besides, people tend to develop meaningful relationships in an attempt to build personal resilience, 
while the supports that aid such relationships are provided by the institutions and the communities provide the platform for such relationships to thrive and encourage the building of resilience. ${ }^{92}$ Resilience as a holistic and multifaceted paradigm encompasses the individual, community, and institution. To research the resiliency level of an individual, researchers have made three distinct stages of resiliency represented as the child, adolescent, and adult. ${ }^{72,96,93}$

\section{Community resilience}

Researchers have over the years viewed the community resilience discourse with a perception that resilience in a disaster scenario comes from the individuals within the community. Since resilience comes from the individual within the community, then collective actions among the individuals instinctively translate to community resilience. .4,95 $^{9}$ Community resilience has some underpinning layers of individual activities which is a direct result of collective individual resilience capacities within the community. ${ }^{96}$ Such underpinning layers revolve around the combination of potential and real resources, possession of durable networks and relationships which Bourdieu ${ }^{53}$ refers to as social capital. It has the potential of enhancing the resilience level of vulnerable communities at risk of any disaster. Community resilience is an indication of the ability of the community not to bounce back, rather, they bounce forward after any disaster episode. This is because, bounce back indicates the ability of the vulnerable to return to a predisaster status which is not achievable, fails to come to terms with the present reality of devastation occasioned by the disaster. At the same time, bounce forward summarises community stability in the context of altered realities occasioned by the disaster scenario. ${ }^{66}$

\section{Characteristics of a resilient community}

Specific characteristics displayed in vulnerable communities during any disaster scenario have embedded components of resilience because of the dynamics of the economic and social circumstances of the community. These characteristics facilitate sustainable lifestyles within the community which further engenders the building of collective resilience during and after any disaster. ${ }^{95}$ Also, Masten ${ }^{96}$ have over the years compiled relevant literature regarding key indicators that engender community resilience in vulnerable communities. These indicators that engender community resilience during any disaster scenario include collective efficacy, ${ }^{97}$ social capital, ${ }^{98,99}$ social trust, ${ }^{100}$ social support, ${ }^{101}$ leadership ${ }^{102,103}$ and emergency preparedness. ${ }^{32,101}$

Community resilience is not a stand-alone notion; instead, physical, and social components underpin it. The physical component involves taking into cognisance the ability of the physical structures within the community to withstand the impact of any disaster. The social mechanism involves considering the sensitivities of individuals and the entire community. It also involves the ability of community members to have a fair knowledge of the chronology, nature and magnitude of previous disasters that have befallen the community and the available social networks, norms, and forms of capital. ${ }^{104}$ There are some characteristics inherent in a resilient community that are peculiar and crucial to the community because it marks the beginning of the collective will to sacrifice and survive in a disaster situation.

\section{Methods and materials}

The study adopted the in-depth case study approach to comprehending the complex phenomenon of access to power and flood disaster resilience in the Orashi region. Flyvbjerg ${ }^{95}$ asserts that the application of the case study approach engenders the production of contextually reliant knowledge. The case study further represents an adaptive method to research that would develop a more nuanced understanding of reality as constructed by local actors. The complexity of the study area involved several actors from diverse ethnic, social, political, cultural, and economic backgrounds. To understand the dynamics associated with this complexity, and get an in-depth perception of the people, a case study for each local government area was deemed the best fit. Focus group discussions were held in each of the case study sites and semi-structured interviews to get participants.

A total of thirty-two interviews were conducted; seven interviews for each local government area which involved community members, opinion leaders, traditional rulers, present and past political office holders -also, one interview with the non-governmental organisations (NGOs), one from a faith-based organisation (FBO) and two from specialised government agencies that participated during the floods. Three out of the four proposed focus groups were successfully conducted. The process of recruiting the participants started with a meeting with the kings of each clan, who made referrals to the chairmen of the community development committee (CDC). The $\mathrm{CDC}$ chairman then contacted the town crier to proclaim around the community inviting those whose source of livelihood was affected during the flood. After the submission, a second selection process was undertaken to get a balanced mix of participants based on their occupation and gender to get different perceptions of their experiences.

Other interviewees in the research came to participate through referrals from the key gatekeepers. These key gatekeepers were the kings of the clans in case study one and three, a former local government chairman in case study two who incidentally was the chairman during the flood. Interviewees who were representatives of the non-governmental organisations (NGOs), faith-based organisations (FBOs), government ministries, departments, and agencies (MDAs) were recruited to participate based on their level of participation during the flood, availability, and willingness to participate in the research.

The analysis of the field data was done using the deductive thematic analysis (top-bottom), as the process entails going through several stages. It started with several stages of reduction (coding) along the line of the theoretical framework. The stages involve compressing the data before coding them to fit into the existed deduced themes of field, habitus, capital, and power Figure 2.

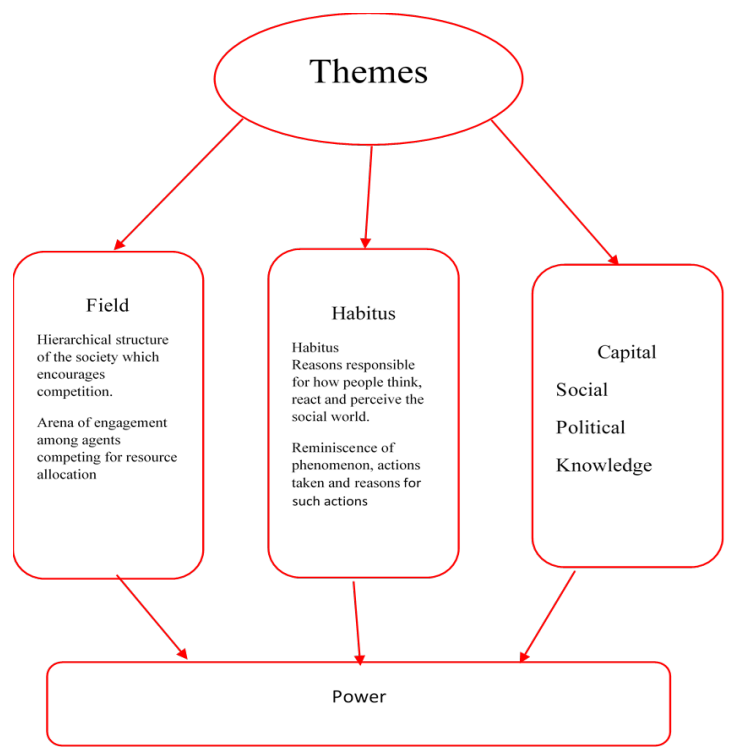

Figure 2 Deduced Themes from the Theoretical Framework of the Research. Source: Brown, 2019. 


\section{Results and discussion}

\section{Field}

In the course of the research, four (4) field sites were identified based on the characteristics in reference to their predominant actors which were used as primary unit of sampling in the study area. In case study one, the location was Abua/Odual Local Government Area which is characterised as peaceful field and in case study two, the location was Ahoada-East Local Government Area characterised as a traditional governed field. The other case studies are case study three, located in Ahoada-West Local Government Area as a politically led field while case study four is located in Ogba/Egbema/Ndoni Local Government Area is characterised as a violent field.

The field in this case study in Abua/Odual local government area was a very peaceful one where all actors had their social positions which gave them access to the arena. The king of the Odual clan who is in charge of the traditional governance structure in the clan, and the then chairman of Abua/Odual local government were the principal actors who participated in the struggle for the control of the resources in the field. However, the struggle for resources was less intense and minimal because there was no conflict of interest between the king of the clan and the local government chairman in the field of engagement. The king of the clan had access to more resources as a result of the goodwill and further interactions between the king and the local donors; some past and present political office holders, entrepreneurs, philanthropists, and the bourgeois who are from that clan.

The second case study site which is Ahoada East Local Government Area is grossly populated by the Ekpeye clan was a traditionally governed field. This is because the king of the Ekpeye clan is a highly revered king to the point of being deified as an incarnate of their ancestors. As such, nobody challenged the king in the decisions taken especially in distributing most of the relief materials such as donated foodstuffs, clothing, medical supplies, sanitary materials, and cash gifts in addition to the temporary shelter provided for the vulnerable affected people. The community kings stood as the intermediary between the family chiefs and community development committees (CDCs) in every community. The CDC worked directly with the youth groups and other members of the community that do not actively participate in any group like the infirm, the aged, pregnant women, young children, physically and mentally challenged and visitors. The male-dominated elders' council interact actively with the family chiefs, but weakly with the youth, the CDCs, and the women group. The strength of the relationship in this case study depends on the role of the group towards building the resilience of the affected people and the flow of the resources during the flood. A point to note in this scenario, the king relatively had access to more resources than the local government chairman.

For case study three which is Ahoada West Local Government Area, it was a politically governed field with a mix of both Ekpeye and Engenni Clans that is mostly populated by the Engenni clan. Besides, the study tilts towards the Engenni clan because they were adversely affected by the flood disaster then. The king of the Engenni clan in this circumstance was not able to access the relief materials because the government and other donors preferred to interact with the established and functional flood management committee at the local government area in which the chairman is the head. Since the chairman in addition to other political associates were entirely in charge of the relief materials, they decided what happened to the affected people and relief materials. In an attempt to achieve their decision to control the flow of the relief materials, they excluded the traditional actors and designated the camps for the displaced people without inputs from them. The political actors accessed all the relief materials received from the conventional donors, and at the same time allocated the relief materials through the engagement of the youths and CDCs of selected communities to assist in the distribution process.

The field in the fourth case study site which is Ogba/Egbema/ Ndoni Local Government Area was a violent field as it witnessed several horizontal and vertical interactions among actors with varying social positions competing to access and control the flow of the limited resources given to the local government area. From the interactions that ensued during the flood, it was evident that this case study site had political, traditional, and violent actors (youths engaged in rural gangsterism). The political actors consist of the local government chairman, councillors and their associates headed by the local government chairman. The traditional actors consist of the king of the clan, kings of other communities, and family chiefs in every community, the community development committee members (CDCs), the youth and the women group with the king of the clan as the head. While the new entrants into the field were the violent armed gangs headed by their various gang leaders, all these actors contested for the resources at stake due to the abundance of oil and gas deposits and exploration companies. Competing for the resources in the field was intense and fierce between the political and traditional actors on one side, and between the political actors and the violent gangs on the other side which culminated into a dysfunctional field. It was such that to access more resources in the disjointed field, the political actors allied with the violent actors to compete and displaced the traditional actors.

\section{Power}

Power in this context indicates how those who had the symbolic power within the local government used it to influence decisions and controlled the flow of resources during the flood. They include the local government chairman, the councillors, some past political office holders and the king of the clan. They were the principal actors in the field, which enabled them to collect and allocate the resources that accrued to the local government area. They used the power derived from being political actors to make decisions that changed the course of actions of the vulnerable population by relocating them during the flood which would not have happened because of the paucity of both human and material resources. From the findings of the research, it was evident that in case study one, the king of the Odual Clan leading one of the most vulnerable groups during the flood episode had access to more contacts and resources and solicited further assistance from friends and conventional donors.

However, the power was evenly applied by both the political and traditional actors which enabled them to establish a balanced power-sharing situation in the field. Two participants in the research confirmed that the political and traditional actors contributed towards their survival during and after the flood:

The politicians from this local government area came and decided that we should move to Abua. That was the last thing we would have done on our own because we were thinking of moving up to where the water did not reach our community. Also, we do not even have enough money to pack most of our valuables. If not for the chairman and his group who gave us something (money) through his highness (king) (Respondent 5, FGD 1).

During the flood, our paramount king looked for help from the people he knows, and they sent some relief materials to us. So many relief materials came from churches, NGOs, and some of the affluent 
community people who did not want to pass through the politicians. However, the king gave everything to the chairman since he was the one in charge of taking care of the affected people in the local government (Interviewee 15 CS 1).

Power in the Ahoada East Local Government Area case study two scenario depicts individuals with legitimate authority to control the flow of symbolic capitals, change the course of flow of the resources and the actions of other people within the community. Several actors exercised power within the field like the king of the clan who was the head of the traditional actors, the clergy and the local government chairman who was in charge of the political actors that controlled the flow of resources during the flood. From the findings of the research, the king of the clan had the authority to control almost everything that happened in the local government area because of the symbol of authority bestowed on the throne and its occupier. This position was used to change the course of actions of the people, for instance, the king decided to relocate the affected people to designated camps at Ahoada town and was supported by the political actors. Another participant in the focus groups session said that the king asked the chairman to assist in providing the boats that conveyed them to safer grounds:

Okay, the local government chairman brought the boat that took me, my family and everybody to Ahoada primary school camp to stay there.... (Respondent 5, FGD 2).

During the flood episode in Ahoada West the case study three site, those who had access to control symbolic capitals were the political actors and the youths in some of the vulnerable affected but neglected communities. Power in this context represented the ability of individuals and groups to deploy their social positions to get officially recognised positions evident in the form of honour, prestige, educational attainment, and political power in the field to access and control the flow of symbolic capitals. Power also represented how those with such privileges deployed it to alter the opinions and actions of the affected people while the flood lasted in their communities. For instance, the political actors used symbolic power to access and control the flow of symbolic resources and actions of the affected people. The continuous influence of the local government chairman regarding making decisions had a direct impact on the vulnerable people because it reflects their inability to make any input, leaving them with no choice but to follow what has been decided by the chairman and associates who were the decision-makers in the community during the flood:

The decision makers during the 2012 flooding are the caretaker government of the community because they were legitimately selected by the governor to control the people of the community. So, the caretaker people are the people that were taking decisions concerning this community during the flood time. They did not ask us anything they stay where they are and decide what the community should... Their action was terrible, then the caretaker chairman was living in Port Harcourt, so the people are in the community.... (Respondent 1, FGD 3).

A participant interviewed said that those who made decisions were associates of the chairman who were appointed or elected:

They are the political office holders from the local government area who were appointed and elected were in charge of everything during the flood. The role they played primarily when the relief materials come to the community was to decide how to discharge ... various camps but some people complained that they did not get to their community with the relief materials. ... because of politics as most of their friends and family benefited from the things that were shared even their friends not living in the camp and not affected came and took some items here .... (Interviewee 14, CS 3).

Power was exercised during the flood in Ogba/Egbema/Ndoni Local Government Area the case study four site witnessed scenarios where all the actors from the violent and traditional fields attempted to control the flow of resources significantly. An alliance was formed between the political and violent actors. This alliance was so powerful that they used it to access all the resources that accrued in that field, and also used the power to determine where, when and who should receive the relief materials by appointing only members of the alliance in the local flood management committee. As an alliance, they benefitted more from the relief materials sent to the victims and further diverted same; however, no disciplinary action was taken by the power holders to control the trend of stealing from the relief materials meant for the affected people. Their action changed the course of action taken by the affected people during and after the flood because it was such that the traditional actors had to create their field to enable them to access the resources at that level. One interviewee said that the political actors excluded the affected people deliberately in the flood management committee to have absolute control of the flow of resources:

All the people who were in the committee were all his political allies, and this is why they did shoddy work since he could not do much even if it came to his knowledge that members of the committee were not doing well. He had no time to investigate or to make any difference because they were his people and whatever they did was fine by him. During the distribution of the relief materials, they decide who gets what in the camps, and they have the sole responsibility of managing the camps. The communities do not interfere in the running of the camp; it was that terrible, but we had no choice then because no member of the affected communities was involved in the decision making and management of the displaced people camps. The chairman of the council single-handedly appointed all the members of the flood committee without consulting anybody from the communities. They just came and decided who and who will be at the camp, unfortunately, those put in there were their friends and family who knew nothing about camp management.... (Interviewee 9, CS 4).

\section{Discussion}

Four distinct fields- peaceful, traditionally led, politically led and violent fields were identified based on the predominant actors found within each field. These identified fields support Bourdieu (1992) assertion that the field represents organised arenas where actors with dominant and subordinate positions interact and engage each other in accessing the specific forms of capital found within that field. Over time, the dominant actors gain full control of the activities in the field because they belong to a specific class, and this subtle action of control engenders class-specific practices within the field. Classspecific practices are often carried out to sustain the monopoly of control by the dominant actors on the limited resources that are at stake in the field because they possess the power of control. Also, the dominant actors have the power that enables them to express superior cultural inclinations over and above those outside of their class within the field, and this power legitimises the appropriation of unequal share of the communal resources that are at stake in the field.

With the continuous appropriation of the collective resources in the field by the dominant actors, the perception of those outside of the dominant class tends to focus on aspiring to become part of the dominant class in the field. This perception of the subordinate class tends to lead them into a situation where they gravitate towards 
those fields that correspond to their dispositions to bypass the fieldhabitus clash. The field-habitus clash is a situation where actors from a lower class aspire and succeed to move into a higher class with little understanding of the workings of the new field and class. Ascending to the field that seems to best match their dispositions, they will become comfortable in their new fields and described with the "fish in water" metaphor as they become used to their new field. ${ }^{48}$ Most times the concept of field is deployed to highlight the social inequalities inherent in society between actors with and without higher educational qualifications regarding the control of the limited resources that are available in the field. The field also represents an arena that enables the creation, exchange and annexation of knowledge goods, services or status regarding competitive positions held by actors. Actors continue to struggle to hold competitive positions in the field to acquire more capital and dominate the arena such that they set the rule of the field since they are relatively in charge of the field. ${ }^{49}$

However, these social hierarchies and laws occasioned by the dominant actors are not permanent in the field. Instead, they are subject to the continuous struggle between the dominant and subordinate actors based on the threshold of capital accessed and controlled by the various actors. Besides, each of these actors tends to hold firm to their positions or change positions according to the capital that can be accessed. As a measure to control access to the field to compete for resources, the dominant actors often introduce stringent criteria to deter other actors from accessing the arena by changing the rules. ${ }^{60}$

Further findings of the research indicate that the political actors had the power to access and control only the resources that accrued to the vulnerable population from the conventional donors, while the traditional actors wielded enormous powers to access and control the flow of economic and social capitals in the field occasioned by the possession of cultural capital. The traditional beliefs system underpinned the authority attached to the throne and enabled the traditional actors to access symbolic capitals, which in this context represents converted economic and social capitals. To access and control these converted capitals actors must possess symbolic power which is comprised of definite and legitimately recognised socially granted title by a state that could be possessed by an individual or group in society. ${ }^{57}$

The kings of the clans across the study area had symbolic power to control the flow of symbolic capitals in the field. Symbolic power possessed and applied by the kings of the clans was such that it could impose subjective opinions on objective individuals and change their courses of action during the flood and reflects Dahl (1957) description of power. The description of power by Dahl (1957) indicates a nearabsolute power of the traditional, political, and violent actors because it could be used to alter the course of thinking and action of the vulnerable groups across the region without the other party having any choice to do otherwise.

Symbolic violence is an offshoot of symbolic capital that signifies a scenario of dominance in which the dominant actors tend to shift the focus of their power away from obvious intimidation with physical violence, coercion, and symbolic influence of the subordinate groups. It is a subtle avenue for dominant actors to express power by deploying dominant systems of representation and meaning on social groups and classes. Symbolic violence thrives with legitimacy evident as the misrecognition of power relations where the dominant systems are usually obscure, misrecognised and assumed as not contributory to the social inequalities. Instead, the subordinate groups recognise the dominant systems as legitimate sources of power because it "lies beyond or beneath the controls of consciousness and will". Bourdieu describes misrecognition as:
"... coercion which is set up only through the consent that the dominated cannot fail to give the dominator... when their understanding of the situation and relation can only use instruments of knowledge that they have in common with the dominator". ${ }^{56}$

Symbolic violence thrived in this scenario with the collaboration of the vulnerable population by its application because dominant actors deployed socio-political discourses that underpin the ideology of its users to generate their mutual consent. Social groups that experienced symbolic violence were objectively incapable of ideating appropriate actions due to the lack of resources to challenge the dominant systems and actors. ${ }^{53}$ Collective approval engenders dominant actors to apply a subtle force that represents an influential force when exercising political power. Collective approval further validates and upholds the application of symbolic violence in the form of social inequalities evident in the ideas and practices which engenders the domination and exclusion of the individuals.

The dynamics of the power relations in each case study site indicate how resilience capacities were built according to the type of capital and resources the vulnerable groups could access at that time. This scenario conforms with Dahl (1957) description of power because these actors altered the course of action of the vulnerable population in the course of the flood. Beyond that, the power possessed and exhibited by these actors further aligns with Gaventa ${ }^{106}$ analogy of power in a real-life scenario. Gaventa ${ }^{106}$ describes such multifaceted power dynamics exhibited as spaces, forms and dimensions of power based on the circumstance and the actors in the field. As evident in each case study site, the exercise of power was in closed spaces by the actors where the vulnerable people were not allowed access to partake in all the decision-making processes. Besides, the level where such decisions were made concerning how to distribute the available resources was at the local level. Also, the power they deployed was visible because the vulnerable population saw how these actors accessed and distributed the resources that accrued in the field.

The watershed moment of this research is the revelation that all the actors acted along tribal lines after using their social positions to access resources. Tribesmen were given priority access to these resources to build their resilience capacities without considering people from other tribes. Hence, this action has led to the emergence of a new lexicon in the annals resilience studies known as tribal capital. ${ }^{107-111}$

\section{Conclusion}

From available research evidence in this study, it is indicative that there is a nexus between the Bourdieusian Theory of practice (field, habitus and capital) and flood disaster resilience capacities building in socially and politically different case study sites across the study area. This is reflected in how most of the vulnerable populations displayed some ingrained dispositions that had been their traditional social cooperating system. The crux of the interactions between the vulnerable population and the actors who had access to symbolic capital in the field was just to have access to the flow of symbolic capitals that would enable them to build up flood disaster resilience capacities. Their perceptions and actions are embedded dispositions that indicate layers of indigenous perceptions relating to the dynamics of power in the building of flood disaster resilience capacities that has over time become the norm in their communities. Actors build their resilience capacities based on their habitus, which informs the level of capital that could be accessed. Such a scenario reflects Bourdieu ${ }^{55}$ description of habitus as embedded dispositions displayed by individual or group which hinges on the establishment of the knowledge of the history of a phenomenon as time progress. Besides, the strand of power that was accessed and used in the allocation and 
subsequent distribution of the relief materials during the flood episode underpins Dahl (1957) opinion of power because those who had access to power then used it near absolutely without due consultations with the vulnerable population. Also, the spaces and levels where decisions regarding the allocation and distribution of the relief materials were way out of the reach of the vulnerable populations. Thus, making Gaventa $^{106}$ description of spaces and levels of power is very valid because all these contributed to the establishment of dynamics of power relations as a resilience capacity builder in a flood disaster scenario in the Orashi region of Rivers State, Nigeria.

\section{Acknowledgments}

None.

\section{References}

1. Hirabayashi Y, Mahendran R, Koirala S, et al. Global Flood Risk Under Climate Change. Nature Climate Change. 2013;3(9):816.

2. Field CB, Barros V, Stocker TF, et al. Managing the Risks of Extreme Events and Disasters to Advance Climate Change Adaptation: Special Report of the Intergovernmental Panel on Climate Change. Cambridge, United Kingdom: Cambridge University Press. 2012.

3. Vormoor K, Lawrence D, Heistermann M, et al. Climate Change Impacts on the Seasonality and Generation Processes of Floods in Catchments with Mixed Snowmelt/Rainfall Regimes: Projections and Uncertainties. Hydrology and Earth System Sciences Discussions. 2014;11(6):6273-6309.

4. Veijalainen N, Lotsari E, Alho P, et al. National Scale Assessment of Climate Change Impacts on Flooding in Finland. Journal of Hydrology. 2010;391(3-4):333-350.

5. He Y, Pappenberger F, Manful D, et al. Flood Inundation Dynamics and Socioeconomic Vulnerability Under Environmental Change. In: Hossain F editor. Vulnerability of Water Resources to Climate. Climate Vulnerability, 5. Elsevier Sciences, 2013. p. 241-255.

6. Li C, Chai Y, Yang L, et al. Spatio-temporal Distribution of Flood Disasters and Analysis of Influencing Factors in Africa. Natural Hazards. 2016;82(1):721-731

7. Israel AO. Nature, the Built Environment and Perennial Flooding in Lagos, Nigeria: The 2012 Flood as a Case Study. Urban Climate. 2017;21:218-231.

8. Pincetl S. Nature, Urban Development and Sustainability-What New Elements Are Needed for a More Comprehensive Understanding? Cities. 2013;29:S32-S37.

9. Whitford V, Ennos AR, Handley JF. City Form and Natural Process Indicators for the Ecological Performance of Urban Areas and Their Application to Merseyside, UK. Landscape and Urban Planning. 2001;57(2):91-103.

10. McGarigal K. FRAGSTATS Help. Documentation for FRAGSTATS. $2014 ; 4$.

11. Pilla F, Gharbia SS, Lyons R. How Do Households Perceive Flood-Risk? The Impact of Flooding on the Cost of Accommodation in Dublin, Ireland. Science of the Total Environment. 2009;650:144-154.

12. Posthumus H, Hewett C, Morris J, et al. Agricultural Land Use and Flood Risk Management: Engaging with Stakeholders in North Yorkshire. Agricultural Water Management. 2008;95(7):787-798.

13. Agada S, Nirupama N. A Serious Flooding Event in Nigeria in 2012 With Specific Focus on Benue State: A Brief Review. Natural Hazards. 2015;77(2):1405-1414

14. Tami AG, Moses O. Flood Vulnerability Assessment of Niger Delta States Relative to 2012 Flood Disaster in Nigeria. American Journal of Environmental Protection. 2015;3:76-83.
15. Tesi GO, Iwegbue C, Emuh FN, et al. Lagdo Dam Flood Disaster of (2012). An Assessment of the Concentrations, Sources, and Risks of PAHs in Floodplain Soils of the Lower Reaches of River Niger, Nigeria. Journal of Environmental Quality. 2016;45(1):305-314.

16. Tawari-Fufeyin P, Paul M, Godleads AO. Some Aspects of a Historic Flooding in Nigeria and Its Effects on some Niger-Delta Communities. American Journal of Water Resources. 2015;3(1):7-16.

17. Mmom PC, Aifesehi PE. Vulnerability and Resilience of Niger Delta Coastal Communities to Flooding. IOSR Journal of Humanities and Social Science. 2013;10:27-33.

18. Uyigue E, Agho M. Coping with Climate Change and Environmental Degradation in the Niger Delta of Southern Nigeria. Community Research and Development Centre Nigeria (CREDC), 2007. p. 24-27.

19. Ologunorisa TE, Adeyemo A. Public Perception of Flood Hazard in the Niger Delta, Nigeria. Environmentalist. 2005;25(1):39-45.

20. Nzeadibe TC, Egbule CL, Chukwuone NA, et al. Indigenous Innovations for Climate Change Adaptation in the Niger Delta Region of Nigeria. Environment, Development and Sustainability. 2012;14(6):901-914.

21. Singh J, Moffat D, Linden O. Defining an Environmental Development Strategy for the Niger Delta. New York, USA: World Bank. 1995.

22. Jack S. That Peace May Reign in Rivers' Orashi Region, January edn, Vanguard Media Limited, Lagos, Nigeria. 2018.

23. Ochege FU, Wekpe VO, Obafemi AA. An Overview of Flood Vulnerability Mapping: Strategy for Disaster Risk Reduction in the Niger Delta Region, Nigeria. Nigerian Journal of Hydrological Sciences. 2008;4(1):13-26.

24. Chacowry A, McEwen LJ, Lynch, K. Recovery and Resilience of Communities in Flood Risk Zones in a Small Island Developing State: A Case Study from a Suburban Settlement of Port Louis, Mauritius. International Journal of Disaster Risk Reduction. 2018;28:826-838.

25. Adger WN. Vulnerability. Global Environmental Change. 2006;16(3):268-281.

26. Whatmore SJ. Mapping Knowledge Controversies: Science, Democracy and the Redistribution of Expertise. Progress in Human Geography. 2009;33(5):587-598.

27. Zhou H, Wan J, Jia H. Resilience to Natural Hazards: A Geographic Perspective. Natural Hazards. 2010;53(1):21-41.

28. Rose A. Economic Resilience to Natural and Man-Made Disasters: Multidisciplinary Origins and Contextual Dimensions. Environmental Hazards. 2007;7(4):383-398.

29. Manyena SB. The Concept of Resilience Revisited. Disasters. 2006;30(4):434-450.

30. Matyas D, Pelling M. Positioning Resilience for 2015: The Role of Resistance, Incremental Adjustment and Transformation in Disaster Risk Management Policy. Disasters. 2015;39(s1):s1-s18.

31. Timmerman P. Vulnerability Resilience and Collapse of Society, A Review of Models and Possible Climatic Applications. Toronto, Canada: Institute for Environmental Studies, University of Toronto. 1981.

32. Ghatak M, Kamal A, Mishra OP. Background Paper Flood Risk Management in South Asia. In Proceedings of the SAARC Workshop on Flood Risk Management in South Asia, 2012. p. 9-10.

33. Adelekan IO. Vulnerability of Poor Urban Coastal Communities to Flooding in Lagos, Nigeria. Environment and Urbanization. 2010;2(2):433-450.

34. Bin O, Polasky S. Effects of Flood Hazards on Property Values: Evidence Before and After Hurricane Floyd. Land Economics. 2004;80(4):490-500.

35. Marzeion B, Levermann A. Loss of Cultural World Heritage and Currently Inhabited Places to Sea-Level Rise. Environmental Research Letters. 2014;9(3):034001. 
36. Chan NW, Parker DJ. Response to Dynamic Flood Hazard factors in Peninsular Malaysia. Geographical Journal. 1996;162(3):313-325.

37. Dhiman R, VishnuRadhan R, Eldho T, et al. Flood Risk and Adaptation in Indian Coastal Cities: Recent Scenarios. Applied Water Science. 2019;9(1):5.

38. McEwen L, Garde-Hansen J, Holmes A, et al. Sustainable Flood Memories, Lay Knowledges and the Development of Community Resilience to Future Flood Risk. Transactions of the Institute of British Geographers. 2017;42(1):14-28.

39. Mavhura E, Manyena SB, Collins AE, et al. Indigenous Knowledge, Coping Strategies and Resilience to Floods in Muzarabani, Zimbabwe. International Journal of Disaster Risk Reduction. 2013;5:38-48.

40. McEwen L, Jones O. Building Local/Lay Flood Knowledges into Community Flood Resilience Planning After the July 2007 Floods, Gloucestershire, UK. Hydrology Research. 2012;43(5):675-688.

41. Scammell MK, Senier L, Darrah-Okike J, et al. Tangible Evidence, Trust and Power: Public Perceptions of Community Environmental Health Studies. Social Science \& Medicine. 2009;68(1):143-153.

42. Robbins D. The Origins, Early Development and Status of Bourdieu's Concept of 'Cultural Capital. The British Journal of Sociology. 2005;56(1):13-30.

43. Bourdieu P. The Logic of Practice. Redwood City, USA: Stanford University Press. 1990.

44. Bourdieu P, Wacquant LJ. An invitation to Reflexive Sociology. Chicago, USA: University of Chicago press. 1992.

45. Ferrare JJ, Apple MW. Field Theory and Educational Practice: Bourdieu and the Pedagogic Qualities of Local Field Positions in Educational Contexts. Cambridge Journal of Education. 2015;45(1):43-59.

46. Bourdieu P. The Practice of Reflexive Sociology (The Paris Workshop) An Invitation to Reflexive Sociology, 1992. p. 216-260.

47. Bourdieu P. Sociology in Question. Thousand Oaks, CA, USA: Sage Publishing. 1993.

48. Grenfell MJ. Pierre Bourdieu: Key Concepts. London, UK: Routledge. 2014

49. Swartz D. Culture and Power: The Sociology of Pierre Bourdieu. Chicago, USA: University of Chicago Press. 1997.

50. Jenkins R. Pierre Bourdieu (rev. ed.). London and New York: Routledge. 2002 .

51. Bourdieu P. The Field of Cultural Production: Essays on Art and Literature. New York, USA: Columbia University Press. 1993

52. Bourdieu P. The Forms of Capital (English Version), Handbook of Theory and Research for the Sociology of Education. 1986. p. 241-258.

53. Bourdieu P. Distinction. A Social Critique of the Judgement of Taste. New York, USA: Routledge. 1984.

54. Bourdieu P. Outline of a Theory of Practice. Cambridge, UK: Cambridge University Press. 1977.

55. Bourdieu P. Practical Reason: On the Theory of Action. Redwood City, USA: Stanford University Press. 1998.

56. Narongchai W, Ayuwat D, Chinnasri O. The Changing of Intergenerational Transfers of Economic Capital in Rural Households in Northeastern, Thailand. Kasetsart Journal of Social Sciences. 2006;37(1):46-52.

57. Bourdieu P. Social Space and Symbolic Power. Sociological Theory. 1989;7(1):14-25.

58. Bourdieu P. Language and Symbolic Power. Cambridge, MA, USA: Harvard University Press. 1991
59. Bourdieu P. Pascalian Meditations, Translated by Richard Nice. $1^{\text {st }}$ ed. Redwood City, CA, USA: Stanford University Press. 2000.

60. Bourdieu P. The Specificity of the Scientific Field and the Social Conditions of the Progress of Reason. Information (International Social Science Council). 1975;14(6):19-47.

61. Bourdieu P. Cultural Reproduction and Social Reproduction. In: J Karabel, et al., editors. Power and Ideology in Education. 1977. p. 487-511.

62. Palmer EA. Cultural Capital and School Success: Implications for Student Achievement. Dissertation Abstracts International. 2002;62(01):125A. UMI No. 9999978.

63. Crossley N. (Net) Working Out: Social Capital in a Private Health Club. The British Journal of Sociology. 2008;59(3):475-500.

64. Field J. Social Capital. London, UK: Routledge. 2008.

65. Davoudi S, Shaw K, Haider LJ, et al. Resilience: A Bridging Concept or a Dead End? Reframing" Resilience: Challenges for Planning Theory and Practice Interacting Traps: Resilience Assessment of a Pasture Management System in Northern Afghanistan Urban Resilience: What Does it Mean in Planning Practice? Resilience as a Useful Concept for Climate Change Adaptation? The Politics of Resilience for Planning: A Cautionary Note: Edited by Simin Davoudi and Libby Porter. Planning Theory \& Practice. 2012;13(2):299-333.

66. Manyena B. Disaster Resilience in Development and Humanitarian Interventions. Nortumbria University: Doctoral Dissertation. 2019.

67. Wreathall J. Properties of Resilient Organisations: An Initial View. Resilience Engineering: Concepts and Precepts, 2006. p. 275-285.

68. Park J, Seager TP, Rao PSC, et al. Integrating Risk and Resilience Approaches to Catastrophe Management in Engineering Systems. Risk Analysis. 2013;33(3):356-367.

69. Zolli A, Healy AM. Resilience: Why Things Bounce Back. Hachette, UK: Simon and Schuster. 2012.

70. Ungar M. Resilience Across Cultures. The British Journal of Social Work. 2008;38(2):218-235.

71. Chaskin RJ. Resilience, Community, and Resilient Communities: Conditioning Contexts and Collective Action. Child Care in Practice. 2008;14(1):65-74.

72. Coleman J, Hagell A. The Nature of Risk and Resilience in Adolescence. Adolescence, Risk and Resilience: Against the Odds. 2007;3:2-16.

73. Pickett ST, Cadenasso ML, Grove JM. Resilient Cities: Meaning, Models, and Metaphor for Integrating the Ecological, Socio-Economic, and Planning Realms. Landscape and Urban Planning. 2004;69(4):369-384.

74. Kendra JM, Wachtendorf T. Elements of Resilience After the World Trade Center Disaster: Reconstituting New York City's Emergency Operations Centre. Disasters. 2003;27(1):37-53.

75. Adger WN, Hughes TP, Folke C, et al. Social-ecological Resilience to Coastal Disasters. Science. 2005;309(5737):1036-1039.

76. Paton D, Johnston D. Disaster Resilience: An Integrated Approach. Charles C Thomas Publisher. 2017.

77. Anderson B, Adey P. Governing Events and Life: Emergency in UK Civil Contingencies. Political Geography. 2012;31(1):24-33.

78. Dore MH, Etkin D. Natural Disasters, Adaptive Capacity and Development in the Twenty-First Century. Natural Disaster and Development in a Globalising World. Routledge, 2003. p. 91-108.

79. Paton D, Johnston D. Disasters and Communities: Vulnerability, Resilience and Preparedness. Disaster Prevention and Management: An International Journal. 2001;10(4):270-277. 
80. Tobin GA, Whiteford LM. Community Resilience and Volcano Hazard: The Eruption of Tungurahua and Evacuation of the Faldas in Ecuador. Disasters. 2002;26(1):28-48.

81. Oven KJ, Curtis SE, Reaney S, et al. Climate change and health and social care: Defining future hazard, vulnerability and risk for infrastructure systems supporting older people's health care in England", Applied Geography. 2012;33:16-24.

82. Bosher L, Carrillo P, Dainty A, et al. Realising a Resilient and Sustainable Built Environment: Towards A Strategic Agenda for the United Kingdom. Disasters. 2007;31(3):236-255.

83. Wilson G. Community Resilience and Environmental Transitions. Oxford, UK: Earthscan. 2002

84. Thomalla F, Downing T, Spanger-Siegfried E. Reducing Hazard Vulnerability: Towards a Common Approach Between Disaster Risk Reduction and Climate Adaptation. Disasters. 2006;30(1):39-48.

85. Allen K. Vulnerability Reduction and the Community-based Approach. Natural Disasters and Development in a Globalising World. 2003. p. 170.

86. Homan J. The Social Construction of Natural Disaster: Egypt and the UK in Natural Disaster and Development in a Globalizing World. London, UK: Routledge, 2003. p. 157-172.

87. Pelling M. Natural Disaster and Development in a Globalizing World. New York, USA: Routledge. 2003.

88. Toft B, Reynolds S. Learning from Disaster: A Management Approach ( $3^{\text {rd }}$ ed), Hampshire, England: Macmillan. 2006.

89. Quarantelli EL. What is a Disaster?: A Dozen Perspectives on the Question. New York, USA: Routledge. 2005.

90. Alexander DE. Confronting Catastrophe: New Perspectives on Natural Disasters. New York, USA: Terra and Oxford University Press. 2000.

91. Rodima-Taylor D, Olwig MF, Chhetri N. Adaptation as Innovation, Innovation as Adaptation: An Institutional Approach to Climate Change. Applied Geography. 2003;33(0):107-111.

92. Doron E. Working with Lebanese Refugees in a Community Resilience Model. Community Development Journal. 2005;40(2):182-191.

93. Mallak LA. Measuring Resilience in Health Care Provider Organisations. Health Manpower Management. 1998;24(4):148-152.

94. Cairns K. Attachment, Trauma and Resilience. London, UK: British Association for Adoption \& Fostering. 2002.

95. Poortinga W. Community Resilience and Health: The Role of Bonding, Bridging, and Linking Aspects of Social Capital. Health \& Place. 2012;18(2):286-295.

96. Masten A, Obradović J. Disaster Preparation and Recovery: Lessons from Research on Resilience in Human Development. Ecology and Society. 2008;13(1):9.
97. Sampson RJ, Raudenbush SW, Earls F. Neighborhoods and Violent Crime: A Multilevel Study of Collective Efficacy. Science (New York, N.Y.). 1997;277(328):918-924.

98. Castleden M, McKee M, Murray V, et al. Resilience Thinking in Health Protection. Journal of Public Health. 2011;33(3):369-377.

99. Chandra A, Acosta J, Meredith LS, et al. Understanding Community Resilience in the Context of National Health Security. Santa Monica, CA, USA: RAND Corporation. 2020.

100. Cacioppo JT, Reis HT, Zautra AJ. Social Resilience: The Value of Social Fitness with an Application to the Military. American Psychologist. 2011;66(1):43.

101. Norris FH, Stevens SP, Pfefferbaum B, et al. Community Resilience as a Metaphor, Theory, Set of Capacities, and Strategy for Disaster Readiness. American Journal of Community Psychology. 2008;41(1-2):127-150.

102. Longstaff PH, Yang S. Communication Management and Trust: Their Role in Building Resilience to "Surprises" such as Natural Disasters, Pandemic Flu, and Terrorism. Ecology and Society. 2008;13(1):3.

103. Baker D. Refsgaard K. Institutional Development and Scale Matching in Disaster Response Management. Ecological Economics. 2007;63(23):331-343

104. Cohen O, Leykin D, Lahad M, et al. The Conjoint Community Resiliency Assessment Measure as a Baseline for Profiling and Predicting Community Resilience for Emergencies. Technological Forecasting and Social Change. 2013;80(9):1732-1741.

105. Flyvbjerg B. Five Misunderstandings About Case-study Research. Qualitative Inquiry. 2006;12(2):219-245.

106. Gaventa J. Finding the Spaces for Change: A Power Analysis. IDS Bulletin, 2006;37(6):23-33.

107. Cote M, Nightingale AJ. Resilience Thinking Meets Social Theory: Situating Social Change in Socio-Ecological Systems (SES) Research. Progress in Human Geography. 2012;36(4):475-489.

108. Demeritt D. The Perception and Use of Public Weather Services by Emergency and Resiliency Professionals in the UK. Report for the Met Office Public Weather Service Customer Group. 2012;2.

109. Dolan P. Prospective Possibilities for Building Resilience in Children, Their Families and Communities. Child Care in Practice. 2008;14(1):83-91.

110. Paton D. Stress in Disaster Response: A Risk Management Approach. Disaster Prevention and Management: An International Journal. 2003b;12(3):203-209.

111. Simonović SP. Floods in a Changing Climate: Risk Management Cambridge, UK: Cambridge University Press. 2012. 